Short code: HEPR

Title: Hepatology Research

ISSN: 1386-6346

Created by: PC

Word version: 11.0

Email proofs to: h-tokai@cj8.so-net.ne.jp

Copyright: (C) 2009 The Japan Society of Hepatology

Volume: ? (Issue: if known)

Cover year: 2009 (Cover month: if known)

Article no.: 556

Article type: OA (Original Article)

Figures: 5; Tables: 0; Equations: 0; References: 23; Words: 3723; First Page: 000; Last Page: 000

Short title running head: Efficacy and limitation of BM transplantation Authors running head: $\mathrm{H}$. Tokai et al.

Correspondence: •• Dr.Hirotaka Tokai, Department of Surgery, Graduate School of Biochemical Sciences, Nagasaki University, 1-7-1 Sakamoto, Nagasaki 852-8051, Japan. Email: h-tokai@cj8.so-net.ne.jp

Received 25 March 2008; revision 1 May 2009; accepted 3 May 2009. 


\title{
Original Article \\ Efficacy and limitation of bone marrow transplantation in the treatment of acute and subacute liver failure in rats
}

\author{
Hirotaka Tokai, Yujo Kawashita, Yuichiro Ito, Kosho Yamanouchi, \\ Mitsuhisa Takatsuki, Susumu Eguchi, Yoshitsugu Tajima and Takashi \\ Kanematsu
}

Department of Surgery, Graduate School of Biochemical Sciences, Nagasaki University, Nagasaki, Japan

Aim: Recent reports have shown that bone marrow cells (BMC) retain the potential to differentiate into hepatocytes. Thus, the BMC have been recognized as an attractive source for liver regenerative medicine. However, it has not been clarified whether BMC transplantation can be used to treat liver damage in vivo. In the present study, we explored whether BMC possess therapeutic potential to treat acute and/or subacute liver failure.

Methods: Fulminant hepatic failure (FHF) was induced by $70 \%$ hepatectomy with ligation of the right lobe pedicle (24\% liver mass), followed by transplantation of BMC into the spleen. Dipeptidyl peptidase IV-positive $\left(\mathrm{DPPIV}^{+}\right) \mathrm{BMC}$ were then transplanted into DPPIV-negative $\left(\mathrm{DPPIV}^{-}\right)$recipients following hepatic irradiation (HIR) in which $70 \%$ of the liver was resected and the remnant liver irradiated.

Results: There was no benefit of BMC transplantation towards survival in the FHF model. DPPIV ${ }^{+}$hepatocytes appeared in the liver tissues of the DPPIV ${ }^{-}$HIR model rats, but DPPIV $^{+}$hepatocytes replaced less than $13 \%$ of the recipient liver.

Conclusion: BMC transplantation may have limitations in the treatment of fulminant or acute liver failure because they do not have sufficient time to develop into functional hepatocytes. Preparative HIR may be beneficial in help to convert the transplanted BMC into host hepatocytes, and provide a survival benefit. Although, However, the precise mechanism warrants further studies.

Key words: bone marrow, fulminant liver failure, irradiation, liver regeneration 


\section{INTRODUCTION}

With an ever-increasing shortage of donor organs for orthotopic liver transplantation, there is a significant need for alternative therapies for liver disease. Isolated hepatocyte transplantation has been successfully reported in experimental animals and in some clinical human cases. ${ }^{1-3}$ However, the procedure of hepatocyte transplantation requires a great number of hepatocytes, and it is still uncertain as to whether or not the transplanted cells can actually engraft in the liver. Recent reports have shown that bone marrow cells (BMC) retain the potential to differentiate into a variety of non-hematopoietic cell lineages, ${ }^{4-8}$ including hepatocytes. Thus, BMC have been recognized as an attractive cell source for liver regenerative medicine. For instance, Sakaida et al. ${ }^{9}$ reported that BMC transplantation exhibited therapeutic potential by reducing liver fibrosis. This therapeutic potential against liver damage is considered to be due to differentiation to mature hepatocytes as well as improvement of intrahepatic microconditions. In addition, fusion between BMC and hepatocytes has been reported, ${ }^{10,11}$ in which the fusion of host hepatocytes and donor BMC can give rise to mature hepatocytes without trans- or dedifferentiation. Such fusion is a new concept, but it is still unknown whether fusion is only a morphological phenomenon or whether it has a significant effect towards regeneration of the liver. On the other hand, previous reports have shown that in vivo cell fusion is an unlikely explanation for the "transdifferentiation" of bone marrow-derived cells into differentiated phenotypes. $^{12,13}$ In any case, investigation of BMC may contribute to the resolution of stem cells or progenitor cells which proliferate to mature hepatocyte, and may result in the promotion of cell transplantation study.

For clinical application, BMC transplantation has an advantage over other cell sources, for example, hepatocytes, embryonic stem cells and hepatic stem cells (oval cell or small hepatocytes), because: (i) the extraction technique of BMC has already been established by hematologists through bone marrow transplantation therapy; (ii) autologous transplantation can avoid rejection; and (iii) BMC may have the potential for self replication and aggressive proliferation.

In the present study, we explored whether BMC could have therapeutic potential in the two distinct, well-established, diseased liver models. One was the surgically induced fulminant liver failure model (FHF model) in which liver failure was caused by $68 \%$ hepatectomy followed by occlusion of the remnant liver lobes. The other was the hepatic irradiation model (HIR model), in which 68\% hepatectomy was performed followed by irradiation of the remnant liver resulting in inhibition of liver regeneration. 


\section{METHODS}

\section{Animals}

Adult male Sprague-Dawley (SD) rats and DPPIV-positive (DPPIV $\left.{ }^{+}\right) 344$ rats were purchased from Japan SLC (Shizuoka, Japan), while DPPIVnegative (DPPIV $\left.{ }^{-}\right) 344$ rats were purchased from Charles River Japan (Tokyo, Japan). All animal care and procedures were performed with the approval of the Nagasaki University Institutional Animal Care and Use Committee.

\section{Surgical animal models}

\section{Induction of FHF model}

Fulminant liver failure was induced as described previously by ourselves. ${ }^{14,15}$ Briefly, the abdomen of male SD rats weighing 270-350 g (7-9 weeks old) was entered through a midline incision. The common pedicle to the right lobes of the liver ( $24 \%$ of the liver) was ligated, and the two anterior liver lobes ( $68 \%$ of the liver) were removed using the standard Higgins and Anderson technique. ${ }^{16}$ The two omental liver lobes ( $8 \%$ of the liver) were left intact (Fig. 1). All surgical preparations and euthanasia were performed under general (diethyl-ether) anesthesia using sterile surgical technique. At the completion of the surgical procedure and every $12 \mathrm{~h}$ after the surgery, each FHF animal received a s.c. bolus of $10 \mathrm{~mL}$ of $5 \%$ dextrose in normal saline.

\section{Induction of HIR model}

The HIR model was generated as described previously. ${ }^{17}$ Anesthesia was induced by i.p. injection $(0.5 \mathrm{~mL} / \mathrm{kg}$ pentobarbital $)$. After aseptic preparation, $68 \%$ partial hepatectomy was performed through a midline incision. Immediately after partial hepatectomy, the animals were placed in a supine position on a surgical board. A jig with a $5 \mathrm{~cm} \times 7 \mathrm{~cm}$ irradiation port was aligned to this platform. Two $1 \mathrm{~cm} \times 2 \mathrm{~cm} \mathrm{lead}$ shields, each $2 \mathrm{~mm}$ in thickness, were wedged under the liver to protect the stomach, kidney, spine and intestines, taking care not to compress the hepatic and aortic vessels. In addition, two lead shields were placed above the chest and the lower abdomen. A Toshiba EXS-300-5 was used (200 kVP, $10 \mathrm{~mA}, 0.5 \mathrm{~mm}$ aluminum, filtration, $43.5 \mathrm{~cm} \mathrm{SSD}$; dose rate, $3.2 \mathrm{~Gy} / \mathrm{min}$ ). The abdomen was then closed in two layers. 


\section{Bone marrow transplantation}

Bone marrow cells were obtained from $\mathrm{DPPIV}^{+}$rats by flushing from the femurs with Dulbecco's modified Eagle medium (Sigma-Aldrich Japan, Tokyo, Japan) using a 21-G needle. The cells were filtered through a cell strainer (Falcon catalog no. 352350) and centrifuged at $200 \mathrm{~g}$ for $5 \mathrm{~min}$ at $4^{\circ} \mathrm{C}$, as previously described. ${ }^{4}$ After washing with phosphate-buffered

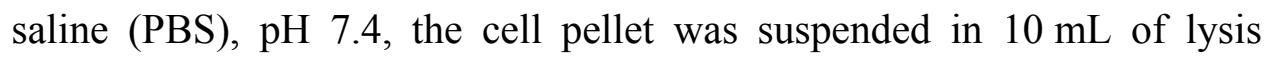
buffer $(150 \mathrm{mM} \mathrm{NH} 4 \mathrm{Cl}, 10 \mathrm{mM} \mathrm{KHCO}, 0.1 \mathrm{mM}$ ethylene diamine tetra acetate). After centrifugation, cells were washed twice in PBS, and the viability of BMC was confirmed to be more than $80 \%$ using Trypan blue dye exclusion.

A small left subcostal incision was made and the spleen was exposed. BMC $\left(2 \times 10^{6}\right.$ cells suspended in $0.5 \mathrm{~mL}$ of physiological saline $)$ were injected under the fibrous capsule of the spleen. The numbers of transplanted BMC referred to the numbers of bone marrow and hepatocyte transplantation, as described previously. ${ }^{4,9,18-20}$ The abdomen was closed in two layers.

\section{Experimental design}

\section{BMC transplantation to FHF model rats}

Fulminant liver failure-induced rats underwent intrasplenic injection of BMC (group I; $n=12$ ) or normal saline (group II; $n=12$ ). Eight rats in each group were monitored until death to determine the survival time, while the other four rats in each group were killed at $12 \mathrm{~h}$ after the BMC transplantation for blood analysis. The experiment for the survival rate and the experiments for biochemical blood analysis were separately done.

\section{BMC transplantation to HIR model rats}

Two days after induction of HIR, BMC (group A; $n=15$ ) or normal saline (group $\mathrm{B} ; n=20$ ) were injected into the spleen. Long-living rats were killed at 1,3 or 5 months after the operation.

\section{Postoperative evaluation}

\section{Blood chemistry}

Blood samples were analyzed for total bilirubin (T-Bil) levels, alanine aminotransferase (ALT) and aspartate aminotransferase (AST) activities in the clinical laboratory. 
After death of the rats, tissues were rapidly cooled and stored at $-80^{\circ} \mathrm{C}$ until analysis. To detect DPPIV enzyme expression, cryostat sections ( $5 \mu \mathrm{m}$ thick) were made. DPPIV stain was performed as previously described. $^{21}$ Briefly, sections were fixed for $5 \mathrm{~min}$ in $95 \%$ ethanol $5 \%$ glacial acetic acid $(99: 1 \mathrm{v} / \mathrm{v})$ at $0^{\circ} \mathrm{C}$ to $-10^{\circ} \mathrm{C}$, followed by a $5-\mathrm{min}$ wash in $95 \%$ ethanol at $4^{\circ} \mathrm{C}$. Air-dried slides were incubated for $10-20 \mathrm{~min}$ at $37^{\circ} \mathrm{C}$ in the substrate solution: $2.5 \mathrm{mg}$ Gly-Pro-4-methoxy-bnaphthylamide (Sigma-Aldrich Japan) dissolved in $150 \mathrm{~mL}$ of dimethylformamide and mixed with $5 \mathrm{~mL}$ of a solution of Fast Blue BB salt (Sigma-Aldrich Japan) in $0.1 \mathrm{M}$ Tris maleate, $0.1 \mathrm{M} \mathrm{NaCl}, \mathrm{pH}$ 6.5. The slides were rinsed two times in $0.14 \mathrm{M} \mathrm{NaCl}$, incubated for $2 \mathrm{~min}$ in $0.1 \mathrm{M} \mathrm{CuSO}_{4}$, and rinsed again in $0.14 \mathrm{M} \mathrm{NaCl}$. The slides were fixed for $10 \mathrm{~min}$ in cold $4 \%$ paraformaldehyde/PBS/5 $\mu \mathrm{M} \mathrm{MgCl}_{2}$ and washed in $0.14 \mathrm{M} \mathrm{NaCl}$. The slides were washed in water and counterstained with Harris hematoxylin. Finally, the percentage of DPPIV cells were counted using Scion image software (Scion Image Beta 4.03 for Windows XP version; Scion, Baltimore, MD, USA) from three independent rats.

\section{Statistical analyses}

Data were analyzed statistically using Mann-Whitney $U$-test and Welch test where appropriate. $P<0.05$ was considered significant. Data are presented as the mean \pm standard deviation. 


\section{RESULTS}

\section{BMC transplantation to the FHF model rats}

\section{Survival time}

In FHF rats, more than $90 \%$ of them died within $48 \mathrm{~h}$ (survival time, $33 \pm 9 \mathrm{~h}$ ), but mature hepatocyte transplantation was able to prolong the survival time $(73 \pm 22 \mathrm{~h}) .{ }^{15}$ However, BMC transplantation did not prolong the survival time. The survival times of group I $(30 \pm 11 \mathrm{~h})$ versus group II ( $28 \pm 14 \mathrm{~h})$ were not significantly different, and the 48 -h survival rate for each group was $12.5 \%$ (Fig. 2).

\section{Blood chemistry}

The average serum T-Bil levels (group I, $2.93 \pm 0.72 \mathrm{mg} / \mathrm{dL}$; group II, $2.82 \pm 0.95 \mathrm{mg} / \mathrm{dL}$ ), AST (group I, $5484 \pm 1627 \mathrm{IU} / \mathrm{L}$; group II, $6803 \pm 3700 \mathrm{IU} / \mathrm{L}$ ) and ALT activities (group I, $3008 \pm 1531 \mathrm{IU} / \mathrm{L}$; group II, $4123 \pm 3868$ IU/L) were not significantly different (Fig. 3). As for the HIR model, data from group A was only available $24 \mathrm{~h}$ after treatment: TBil $0.93 \pm 0.49$, AST $1007 \pm 223$ and ALT $457 \pm 140$.

\section{BMC transplantation to the HIR model rats}

\section{Survival rate}

Thirteen of 15 rats in group A survived up to 1 month, but 13 of 20 rats in group B did not survive up to 1 month. The survival times of group A $(127 \pm 109$ days $)$ versus group $B(35 \pm 50$ days $)$ were significantly different. The 150-day survival rate of group A (74.2\%) was significantly greater than group B (17.1\%) (Fig. 4).

\section{DPPIV staining}

Morphologically, clusters of DPPIV ${ }^{+}$hepatocytes were found in the liver of rats in group A (Fig. 5a) but there were no DPPIV ${ }^{+}$cells in the liver in group B. The DPPIV ${ }^{+}$hepatocytes in the rats in group A were considered to be bone marrow-derived hepatocytes that replaced a maximum of $13 \%$ of the recipient liver (Fig. 5b). 


\section{DISCUSSION}

We tested whether BMC have the potential to support the diseased liver in two distinct, well-established animal models. One is the surgically induced FHF model, in which liver failure is caused by $68 \%$ hepatectomy followed by occlusion of the remnant liver lobes. The other is the HIR model, in which $68 \%$ hepatectomy is performed followed by irradiation of the remnant liver resulting in fatal liver failure associated with inhibition of liver regeneration. Of note, the HIR model does not emulate human liver disease, but an artificial model to show proliferative advantage to the transplanted cells. Radiation induces critical deterioration in the liver microenvironment that is conducive to the selective proliferation of normal, transplanted hepatocytes as demonstrated previously. ${ }^{17,20}$ The precise mechanisms underlying this phenomenon have yet to be elucidated. Radiation is known to inhibit liver growth for extended periods of time; thus, its effect would appear to be similar, at least in principle, to that exerted by retrorsine; blocking that would block of the endogenous hepatocyte cell cycle

Using these models, we demonstrated that BMC may have the potential to morphologically trans-differentiate into hepatocytes in the HIR model. However, our study also demonstrated potential limitations of BMC transplantation in the treatment of fulminant liver failure. In the FHF model, previous studies have demonstrated that mature hepatocyte transplantation can provide survival benefit in liver failure. ${ }^{15,22}$ However, a large number of hepatocytes are necessary to adequately treat liver disease. On the other hand, some investigators have suggested that BMC transplantation can be used to treat chronic liver diseases through its regenerative potential. ${ }^{9}$ Therefore, we investigated the potential of BMC transplantation to treat FHF in an animal model of acute liver failure induced by the loss of a large amount of hepatocytes followed by lethal systemic inflammation.

As a result, BMC transplantation did not exhibit any survival benefit in rats in this FHF model. This may because BMC require certain conditions and/or adequate time to differentiate into functional hepatocytes. Regarding the numbers of transplanted BMC, we injected $2 \times 10^{6}$ cells under the fibrous capsule of the spleen. In previous reports, the numbers of transplanted cells ranged from $10^{6}$ to $10^{7}$ cells. However, the injection of too many cells can sometimes cause venous thrombosis. Furthermore, our strategy required fewer cells to treat liver damage; namely, $2 \times 10^{6} \mathrm{BMC}$ were considered sufficient. Accordingly, while BMC transplantation may be promising, acute liver failure may not be a good target for this treatment strategy.

Similar to previous reports that have indicated the potential of BMC to differentiate into various types of cells, DPPIV staining revealed that 
several clusters of hepatocytes exhibited the features of BMC derived from transplanted donor cells in the HIR model. It remains unclear whether transplanted BMC were trans-differentiated into hepatocytes or were fused with the host hepatocytes. However, the presence of DPPIV cells in the HIR model indicates the possibility that these cells are committed stem cells of the liver. This is because the DPPIV ${ }^{+}$hepatocytes are morphologically hepatocytes, but their potential may include selfreplication and vigorous proliferation. Therefore, we anticipate the therapeutic potential of BMC against acute liver injury. In the present study, total replacement of the liver by BMC was not observed, however, several rats in the BMC transplantation group survived longer than those of the control group. Although the etiology of the survival benefit remains unknown, we speculate that BMC transplantation can contribute not only to the repopulation of hepatocytes but also to the improvement of the internal environment of the liver. For instance, it is hypothesized that BMC can contribute to the suppression or resolution of fibrosis in liver cirrhosis or can activate hepatic mesenchymal cells. The "fibrolysis" effect of BMC transplantation has been demonstrated. ${ }^{9}$ Further investigations of the contribution of BMC transplantation to improve the intrahepatic micro-condition are required.

Furthermore, these results suggest that the HIR model itself can be a useful model for cell transplantation in which high-dose irradiation of the liver can injure the host hepatocytes and impart a selective proliferative advantage to the unirradiated donor cells. ${ }^{21,23}$ Histologically, extensive loss of hepatocytes occurs in the irradiated liver, and various degrees of micro- and macrovesicular steatosis in the centrizonal areas. Furthermore, preparation of partial hepatectomy induces several chemical growth factors to regenerate the remnant liver. We speculate that this particular condition may lead to selective growth of transplanted cells. Thus, the HIR model could be applied to clinical cases, such as congenital or metabolic liver disease, by transplantation of normal cell sources. Cell transplantation therapy is expected to become a novel and effective therapy against liver diseases, as an alternative to liver transplantation. However, cell transplantation therapy requires a large number of donor cells that are able to survive in the host liver. In general, a sufficient number of mature hepatocytes cannot be provided, but stem cells may solve this problem. Among the currently available stem cell sources, BMC have several advantages, as previously described. To further elucidate this, further studies concerned with the evaluation of pure bone marrow stem cells and the etiology of trans-differentiation to hepatocytes are needed. Furthermore, it is still unknown whether "so called" bone marrow-derived hepatocytes are actually trans-differentiated from BMC or fused with $\mathrm{BMC}$. We are currently investing the cell fusion phenomenon to determine the contribution of BMC to support liver failure. 
In conclusion, BMC transplantation may have limitations in the treatment of these models of fulminant or acute liver failure because they do not have sufficient time to develop into functional hepatocytes. Preparative HIR may be beneficial and help convert the transplanted BMC into host hepatocytes to provide survival benefit, although the precise mechanism warrants further investigation. 


\section{REFERENCES}

1 Mito M, Kusano M, Kawaura Y. Hepatocyte transplantation in man. Transpl Proc 1992; 24: 3052-3.

2 Strom SC, Fisher RA, Thompson MT et al. Hepatocyte transplantation as a bridge to orthotopic liver transplantation in terminal liver failure. Transplantation 1997; 63: 559-69.

3 Fox IJ, Chowdhury JR, Kaufman SS et al. Treatment of the CriglerNajjar syndrome type I with hepatocyte transplantation. $N$ Engl $J$ Med 1998; 338: 1422-6.

4 Petersen BE, Bowen WC, Patrene KD et al. Bone marrow as a potential source of hepatic oval cells. Science 1999; 284: 1168-70.

5 Theise ND, Nimmakayalu M, Gardner R et al. Liver from bone marrow in humans. Hepatology 2000; 32: 11-16.

6 Alison MR, Poulsom R, Jeffery R et al. Hepatocytes from nonhepatic adult stem cells. Nature 2000; 406: 257.

7 Krause DS, Theise ND, Collector MI et al. Multi-organ, multi-lineage engraftment by a single bone marrow-derived stem cell. Cell 2001; 105: 369-77.

8 Lagasse E, Connors H, Al-Dhalimy M et al. Purified hematopoietic stem cells can differentiate into hepatocytes in vivo. Nat Med 2000; 6: 1229-34.

9 Sakaida I, Terai S, Yamamoto $\mathrm{N}$ et al. Transplantation of bone marrow cells reduces CCl4-induced liver fibrosis in mice. Hepatology 2004; 40: $1301-11$.

10 Vassilopoulos G, Wang PR, Russell DW. Transplanted bone marrow regenerates liver by cell fusion. Nature 2003; 422: 901-4.

11 Alvarez-Dolado M, Pardal R, Garcia-Verdugo JM et al. Fusion of bone-marrow-derived cells with Purkinje neurons, cardiomyocytes and hepatocytes. Nature 2003; 425: 968-73.

12 Ianus A, Holz GG, Theise ND, Hussain MA In vivo derivation of glucose-compotent pancreatic endocrine cells from bone marrow without evidence of cell fusion. J Clin Invest 2003; 111: 843-50.

13 Harris RG, Herzog EL, Bruscia EM, Grove JE, Van Arnam JS, Krause DS. Lack of a fusion requirement for development of bone marrowderived epithelia. Science 2004; 305: 90-3.

14 Eguchi S, Kamlot A, Ljubimova J et al. Fulminant hepatic failure in rats: Survival and effects on blood chemistry and liver regeneration. Hepatology 1996; 24: 1452-9.

15 Eguchi S, Lilja H, Hewitt W, Middleton Y, Demetriou AA, Rozga J. Loss and recovery of liver regeneration in rats with fulminant hepatic failure. J Surg Res 1997; 72: 112-22. 
16 Higgins GM, Anderson RM. Restoration of the liver of the white rat following partial surgical removal. AMA Arch Pathol 1931; 12: 186202.

17 Guha C, Sharma A, Gupta S et al. Amelioration of radiation-induced liver damage in partially hepatectomized rats by hepatocyte transplantation. Cancer Res 1999; 59: 5871-4.

18 Guo D, Fu T, Nelson JA, Superina RA, Soriano HE. Liver repopulation after cell transplantation in mice treated with retrorsine and carbon tetrachloride. Transplantation 2002; 73: 1818-24.

19 Dabeva MD, Hwang SG, Vasa SR et al. Differentiation of pancreatic epithelial cells into hepatocytes following transplantation into rat liver. Proc Natl Acad Sci USA 1997; 94: 7356-61.

20 Malhi H, Gorla GR, Irani AN, Annamaneni P, Gupta S Cell transplantation after oxidative hepatic preconditioning with radiation and ischemia-reperfusion leads to extensive liver repopulation. Proc Natl Acad Sci USA 2002; 99: 13114-19.

21 Takahashi M, Deb NJ, Kawashita Y et al. A novel strategy for in vivo expansion of transplanted hepatocytes using preparative hepatic irradiation and FasL-induced hepatocellular apoptosis. Gene Ther 2003; 10: 304-13.

22 Ribeiro J, Nordlinger B, Ballet F et al. Intrasplenic hepatocellular transplantation corrects hepatic encephalopathy in portacaval-shunted rats. Hepatology 1992; 15: 12-18.

23 Guha C, Parashar B, Deb NJ et al. Normal hepatocytes correct serum bilirubin after repopulation of Gunn rat liver subjected to irradiation/partial resection. Hepatology 2002; 36: 354-62. 


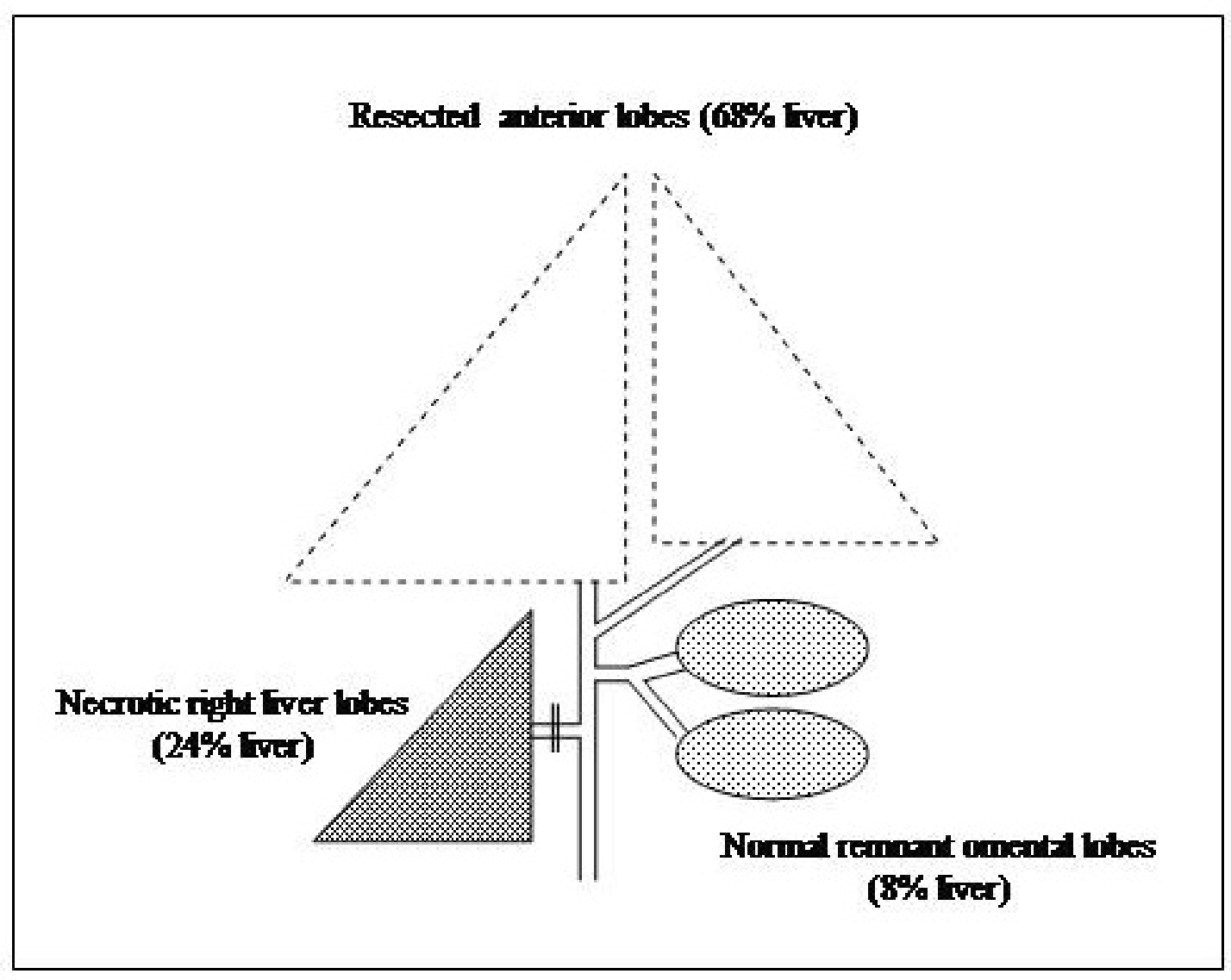

Figure 1 Schematic diagram depicting the technique used to induce fulminant hepatic failure in this model. Two anterior lobes $(68 \%$; median lobe and left anterior lobe) were resected and the right lobes $(24 \%)$ were rendered necrotic. Only the omental lobes $(8 \%)$ were left intact. 


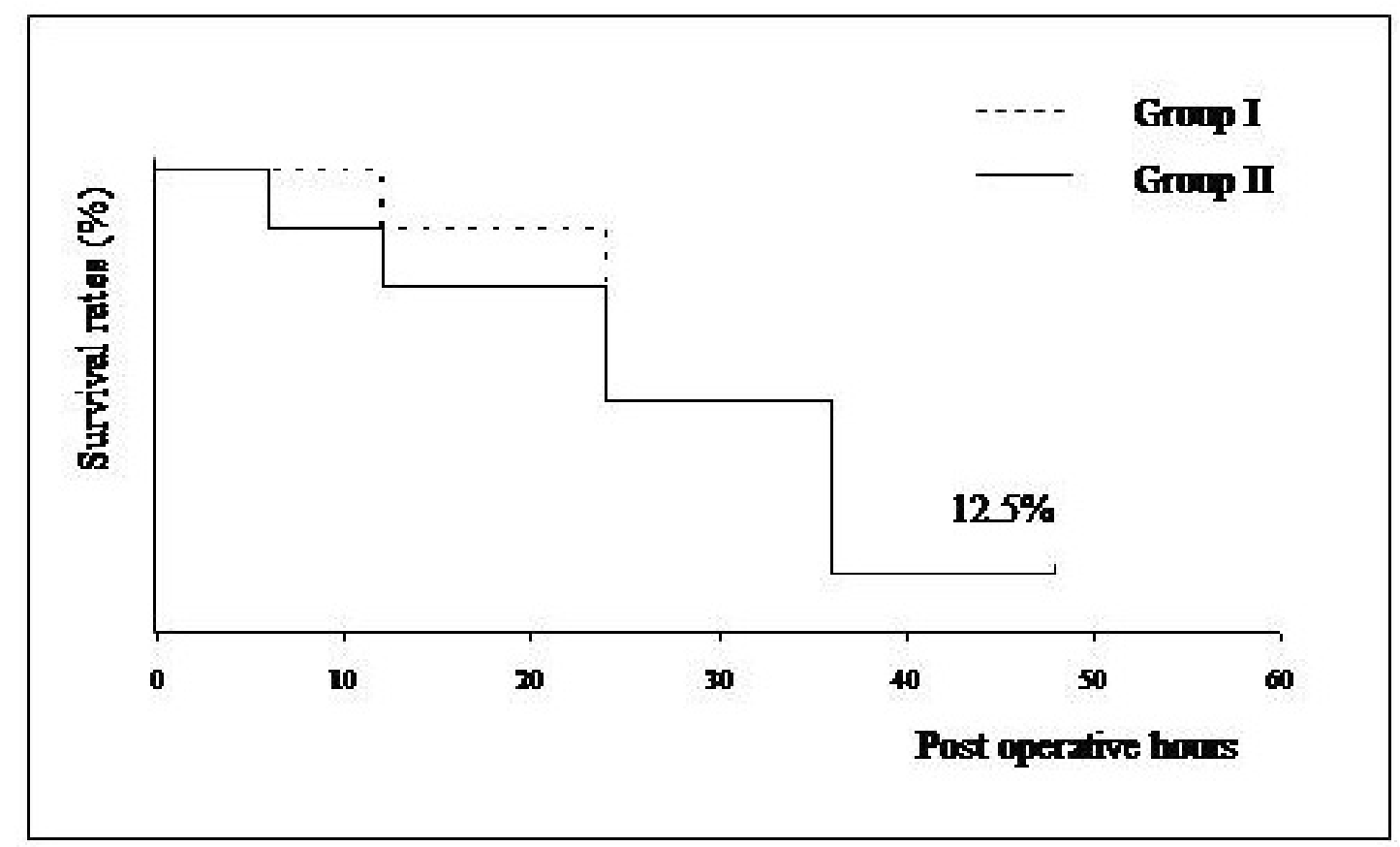

Figure 2 Effect of BMC in the treatment of FHF model. Comparison of the survival rate for Group I vs. Group II was not significant (12.5\%). The mean survival time was $30 \pm 11$ and $28 \pm 14 \mathrm{~h}$ for Group I and Group II, respectively. Group I; Acute liver failure with BMC, Group II; Acute liver failure without BMC. 


\section{(mg/dL) T-Bil}
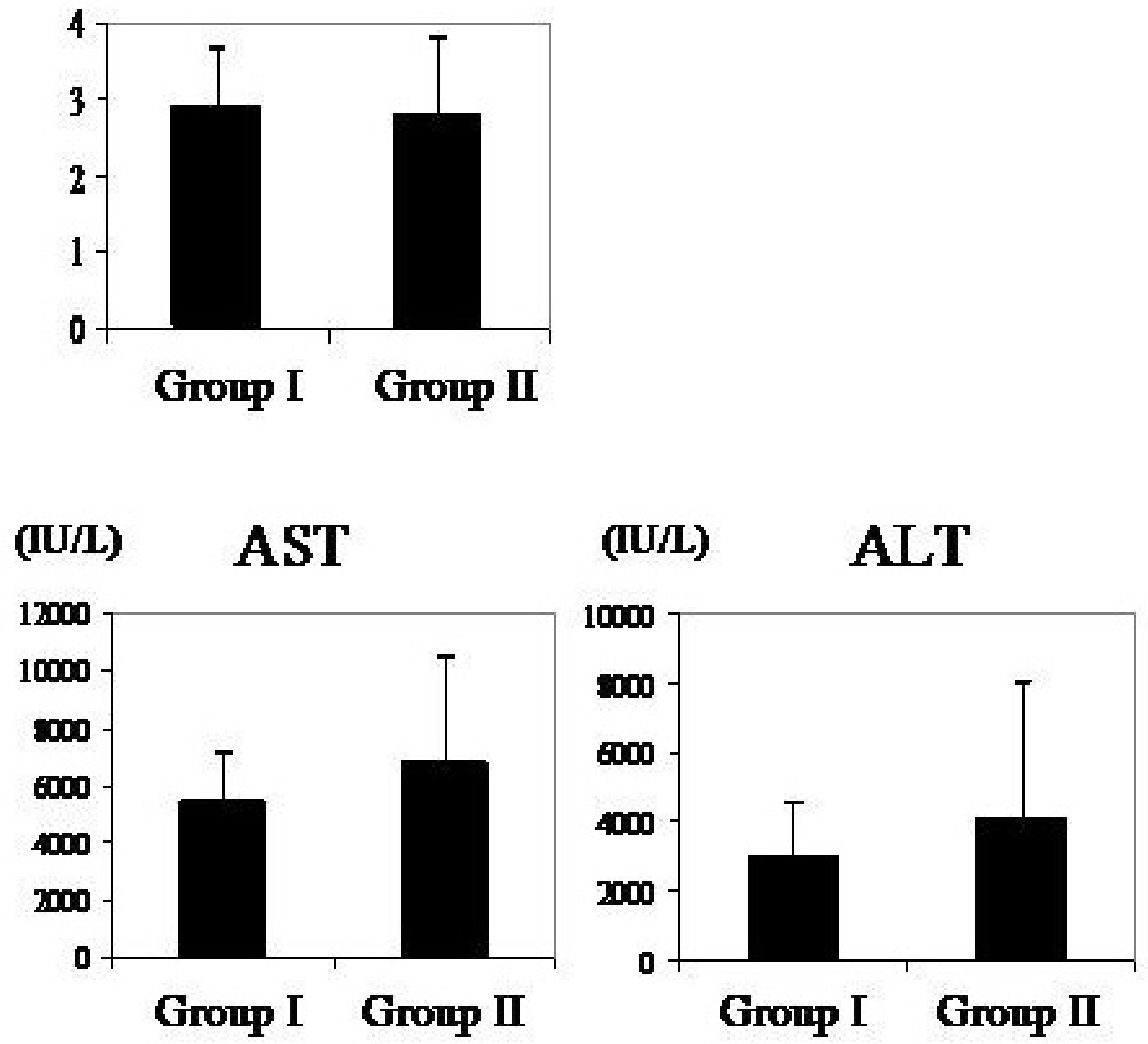

Figure 3 Biochemical changes after BMC treatment in the FHF model. Between groups I and II, the average serum T-Bil levels, and AST and ALT activities $12 \mathrm{~h}$ after treatment were not significant. 


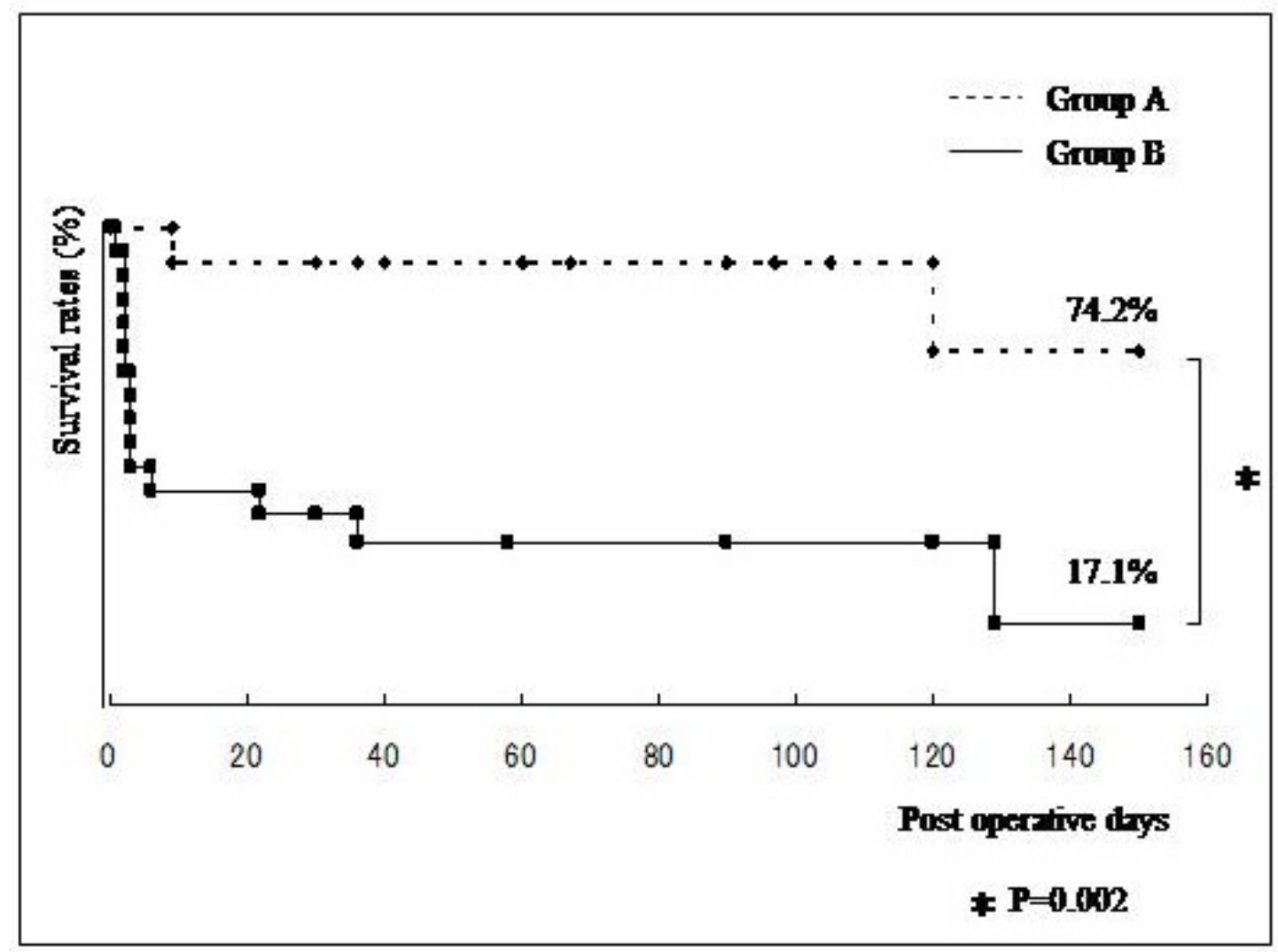

Figure 4 Effect of BMC in the treatment HIR model. The survival rate of group A $(74.2 \%)$ vs. group B (17.1\%) was significantly improved $(P=0.002)$. 


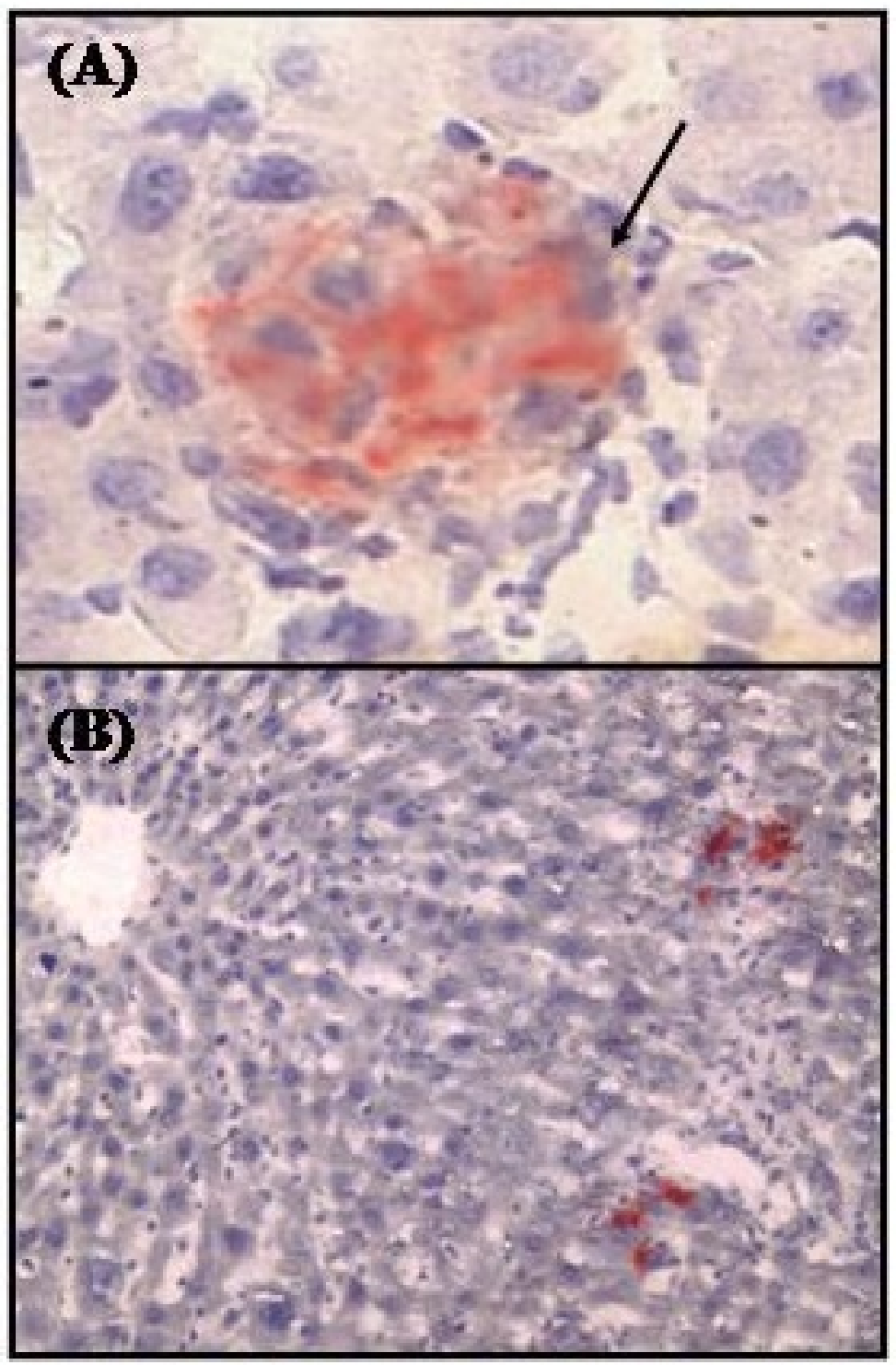

Figure 5 (a) Histological presence of bone marrow-derived hepatocytes. Clusters of DPPIV ${ }^{+}$hepatocytes were found in the livers of rats from group A (arrow), but no DPPIV ${ }^{+}$cells were found in the livers of group B rats. (b) DPPIV ${ }^{+}$hepatocytes replaced the recipient liver to a maximum of $13 \%$. 